\title{
A spatially enabled framework for habitats and species management system - Architecture and case study
}

\author{
Dr. Cristina-Violeta Oana \\ Esri Romania \\ 8 Roma str. apt. 1, sector 1 , \\ Bucharest, 011774, Romania \\ +40-21-233.90.87 \\ cov_gps@esriro.ro
}

\author{
Dr. Cristian Vasile \\ Esri Romania \\ 8 Roma str. apt. 1, sector 1 , \\ Bucharest, 011774, Romania \\ +40-21-233.90.87 \\ cvasile@esriro.ro
}

\author{
Simona Ipate (Staiculescu) \\ Esri Romania \\ 8 Roma str. apt. 1, sector 1 , \\ Bucharest, 011774, Romania \\ +40-21-233.90.87 \\ sstaiculescu@esriro.ro
}

\begin{abstract}
National Parks represent a natural heritage resource which is monitored through periodical observations of species in their territory and inventories of habitats and species within its boundaries. However, the management of the natural habitats and species is often critical, due to the difficulty of collecting data in a standard and interoperable form and dissemination to other available information systems. This paper is focused on the development of the geospatial architecture framework and applications required for an efficient inventory and mapping of natural habitats and wild species of community interest and undertaking special measures to conserve these species and habitats characteristic to the steppe bioregion. To show the usefulness, efficiency and effectiveness of this spatially enabled applications framework, we present a use case developed and implemented for the decision makers of the "Macin Mountains" National Park Administration and Natura2000 sites: SPA MacinNiculitel and SCI Macin Mountains.
\end{abstract}

\section{Categories and Subject Descriptors}

H.3.5 [Information storage and retrieval]: Online Information Services - Web-based services.

\section{General Terms}

Management, Measurement, Design, Reliability, Experimentation, Standardization, Verification.

\section{Keywords}

Biodiversity; GIS; Database; Geoportal; Geospatial Web Services; SDI; metadata.
Permission to make digital or hard copies of part or all of this work for personal or classroom use is granted without fee provided that copies are not made or distributed for profit or commercial advantage and that copies bear this notice and the full citation on the first page. Copyrights for third-party components of this work must be honored. For all other uses, contact the Owner/Author.

Copyright is held by the owner/author(s).

SIGSPATIAL '14, Nov 04-07 2014, Dallas/Fort Worth, TX, USA

ACM 978-1-4503-3131-9/14/11.

http://dx.doi.org/10.1145/2666310.2666475

\section{INTRODUCTION}

One of the greatest challenges facing the world is the need for more effective management of natural resources, with the goals of maintaining the health of environment, conserving biodiversity and facilitating sustainable and equitable development. During the last years, Romania has been in the process of implementing a series of biodiversity conservation projects that are focused on inventorying and mapping natural habitats and wild species of community interest for the major natural protected areas. In the context of EU legislation, regarding the reports on biodiversity conservation (Article 6, Habitats Directive, 1992; Articles 9 and 12, Birds Directive, 2009), assessing the need for biodiversity information has been addressed also by the "Macin Mountains" National Park Administration. They are aware that problems of data heterogeneity, standard consistency and lack of a common spatial information repository can have the most serious consequences for the understanding of biodiversity and for decision making, which has to be accessible to all interested parties and integrated with other relevant information.

The current paper has been tailored to deliver a simple, efficient and cost-effective spatially enabled information system for the biodiversity management, that is based on a three-tier architecture and which seeks to encourage participation of local communities in park management. We do consider that this geospatial applications framework can be successfully implemented to serve biodiversity monitoring purposes at the local and regional level and it is reliable to be extended at the national level.

\section{APPROACH AND METHODOLOGY}

The project was focused on identifying trends in important biodiversity assets of the protected areas and taking into consideration these results in order to guide the activities and further actions in their park management. The information gathered is analyzed and the results are disseminated and used by the Scientific Council of the Protected Area Management Board to take better decisions on the resources management in the protected areas -"Macin Mountains" National Park Natura 2000 sites: SPA Macin-Niculitel and SCI Macin Mountains.

Playing a major role in meeting this biodiversity management, our approach is based on GIS technologies. The methodology focused on development a centralized standard tool to integrate the most efficient field methods, solutions and equipment, the adequate data analysis methods, a biodiversity data model to store data, and a collaborative platform for sharing and disseminating the results. 
The existing data regarding the biodiversity are modelled and being integrated into a centralized geodatabase structure. We developed a workflow for biodiversity data captured from the field and specialized tools in order to support this habitats and species management workflow. All spatial and non-spatial data are analyzed and then there are generated the distribution maps that give us feedback regarding habitats and species of these protected areas. Field data are captured using GPS mobile devices by the scientific experts on monitored species. Data processing includes data migration process into an optimized geodatabase schema compliant with the INSPIRE Directive for Protected Sites, as well as a QA/QC process applied to these data. Data analysis is the most time consuming process.

\section{BIODIVERSITY INFORMATION SYSTEM ARCHITECTURE}

The geospatial applications framework of the habitats and species management systems consists of three-tier architecture (see Figure 1). This framework allows collecting information with different levels of scope in a central database to report on gains and losses in biodiversity across its areas of responsibility. A standardized set of reports, presentations and graphics has been created for each component of the system based on the Common Monitoring Standards [1]. This three-tier architecture is certainly contributing to measuring and reporting on biodiversity integrity.

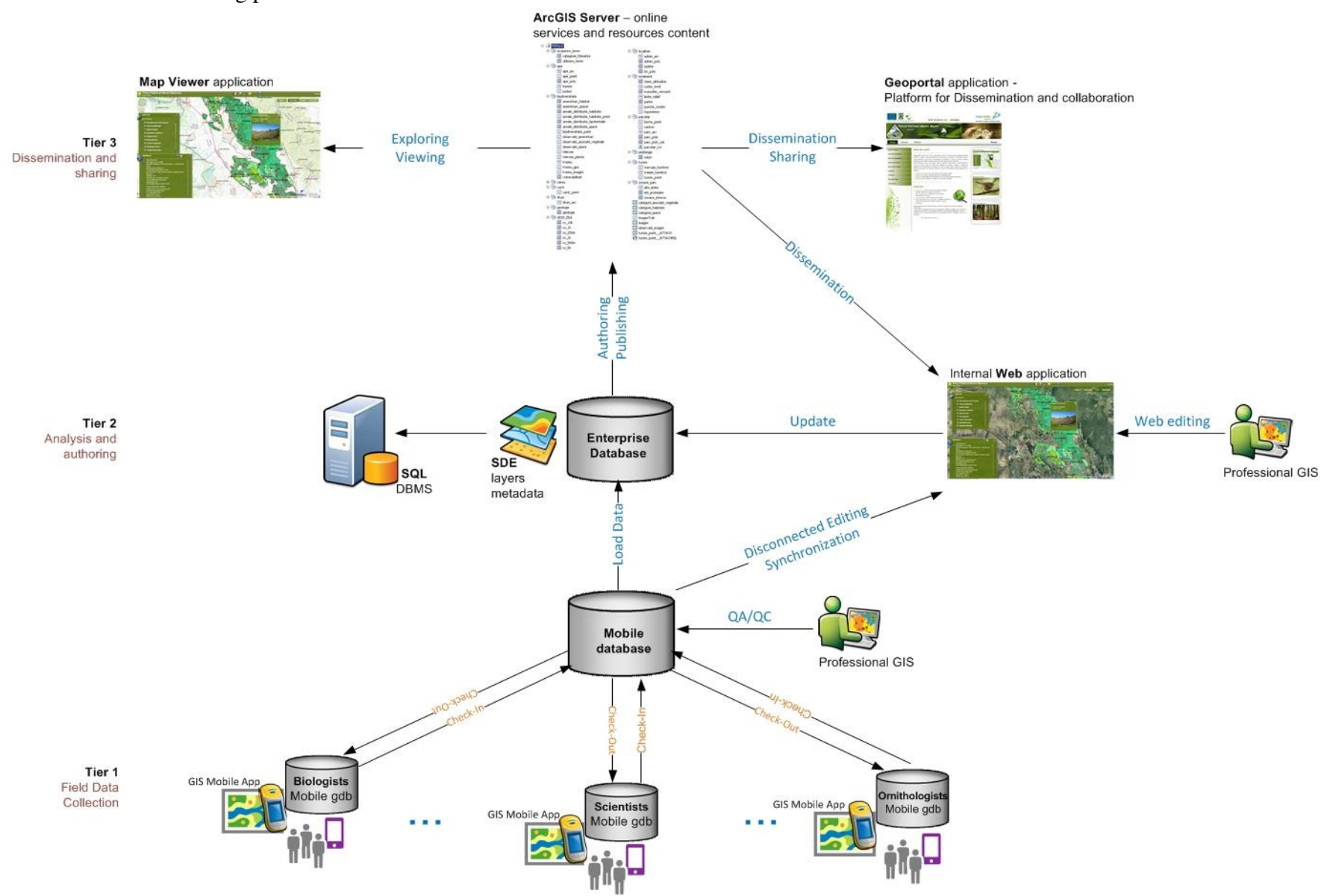

Figure 1. The geospatial architecture framework of the biodiversity information system.

The first tier of the architecture represents an essential part of our solution providing the tools for biodiversity field data collection process and synchronization with the central database.

The middle tier of the diagram indicates the central geospatial database, designed according to INSPIRE Data Specifications for protected areas [2] and the authoring part of the solution. This is dedicated for spatial analysis process in order to assess habitats and species distribution and their conservation status, as well as maps authoring in order to communicate the message geospatially to the decision makers. The core of this central part of the system consists of the biodiversity information content - meaning an enterprise geodatabase available for querying on the web, a complex detailed basemap, downloadable habitats and species distribution maps, survey data, pictures, and other reports.
The third tier of the system enables users to query, display and provide data of flora and fauna of the protected areas using an internet browser instead of downloading or installing any other related objects. The core of this level consists in a geoportal application which is ensuring interoperability and expands access to biodiversity spatial data, metadata, web services and applications as part of the Romanian National Spatial Data Infrastructure and allowing reporting also at a higher level.

\section{4. "MACIN MOUNTAINS" NATIONAL PARK - USE CASE}

This pattern of our geospatial applications framework allows any organization to unlock and leverage their GIS investments throughout their entire organization. There are some organizations 
which are anxious to realize this web GIS vision but there are occasionally those who are not interested or see this vision as problematic to their organization.

The protected area under implementation is a surface of $11,151.82$ hectares named "Macin Mountains" National Park (MMNP) that is divided into two zones: Pricopan Heights and Macin Mountains. This study case includes also Natura2000 sites: SPA Macin-Niculitel and SCI Macin Mountains. The Macin Mountains are situated in the South-East of Romania, respectively in North-West Dobrogea, Tulcea County, between the Danube Valley, Luncaviţa Valley and the Cerna-Horia saddle.

The Macin Mountain area is representing an important connection on the migration routes which follows the Prut and Siret rivers. The variety of ecosystems (land, forest or rocky) mixed with the presence of the aquatic systems close to mountain ridges (Jijila, Sarat and Slatina lakes, etc.), offer the most favorable conditions for transitory or temporary passing and wintering of a great number of species and specimens.

The fauna of the Macin Mountains protected area is very diverse and has a special importance due to the presence of rare and protected species, according to international regulations. This biodiversity resources brings together over 1770 plant species, of which 72 are protected as being rare or vulnerable, and 27 are endemic to the region; 181 bird species, of which 37 are strictly protected internationally, being mentioned in the European Habitats and Birds Directives [3] and Bern Convention; 47 mammal species; 1436 unidentified insect species, with over 900 butterfly species; 11 reptile species and 7 amphibian species.

\subsection{Field data collection and analysis}

Data sources that we had to gather fall into the following categories: (1) catalogues covering the literature of entities names including countries of origin and updating issues; (2) checklists and biotas (floras and faunas), which are complementary tools that provide a basis for a full account of species including descriptions and keys; (3) the associations between plants species and habitats; (4) topographic information; (5) administrative data; (6) Land cover data; (7) EEA reference grids [4] - with different cell size used to mark the presence/absence of a species or habitat; (8) soil data; (9) geology data; (10) data needed for morphometric analysis (slope, curvature, aspect, altitude); (11) Landsat imagery - used for classification; (12) aerial photos - for feature extraction, and other resources.

We have manually collected the list of species and habitats using the Romanian Manual for Interpretation of EU Habitats, and other Natura2000 documentation [5]. The data was designed in a geodatabase structure, according to the data specifications of INSPIRE Directive - Annex I [2]. The attributes and non-spatial data were associated within the geospatial database as appropriate [6].

The geodatabase schema includes the following geospatial themes: land cover, hydrography, morphology, transportation, soils, geology; EEA grid reference system; biodiversity-habitats and species threats areas; field surveys on habitats and species threats, administrative park limits; tourism information and nonspatial tables (habitats, species, plants association).

As part of the entire biodiversity architecture framework, the mobile GIS application allows the scientists to complete the following tasks: view and navigate effectively to the field resources and monitor the location of assets; collect, edit, and real-time update the biodiversity information and share data immediately with other scientists, synchronizing it with the central geodatabase; search and manage a list of features to perform tasks or plan future work.

Data analysis performed for this studied area can be classified in two categories: a) using spatial analysis tools we generated some maps and raster data required for the interpretation of habitats and species distribution; a Landsat imagery were processed using unsupervised classification as a starting point for generating potential habitats distribution in the study areas that were validated further in the field. b) using the generated maps from the first step, collected data and the estimation of the potential habitats distribution, we validated the fields followed by some segregation/aggregation GIS analysis. During the second part of the analysis process, we have also generated the species distribution using the field observations, the species characteristics and their specific habitats.

The vegetation analysis was performed in order to describe the distribution of plant species and to relate observed distribution patterns to biotic and abiotic site factors [7]. The most complex activity during this phase of analysis process was done for mapping the distribution of habitats and their conservation status. To solve this task, we also used GIS technologies in the classification of the images by means of an unsupervised classification method [8]. Spatial association of hydro-geomorphological units with land cover and species distribution permitted us the differentiation of potential habitats.

The results led us to generate the following distribution maps regarding 12 habitats, 21 bird species identified for this studied protected areas-ROSCI0123. Using GIS techniques, we have derived some map books which include map sheets, available at different graphic scales $(1: 200.00,1: 10.000)$, cut out by the European Environment Agency grid reference system.

A few statistical calculations allowed us to quantify the results, reporting the percentage covered by each identified habitat, in the protected area-ROSCI0123: 91Y0-Dacian oak and hornbeam forests (50\%); 91M0-Pannonian Balkanic turkey oak and sessile oak forests $(>10 \%)$; 91AA-Eastern white oak woods $(6 \%)$; $91 \mathrm{I} 0$ *-Euro-Siberian steppic woods with Quercus spp. (1.2\%); 91X0*Dobrogean Beech forests $(0.2 \%)$ which is unique in the world. The habitat 91Z0-Moesian Silver lime woods forests has to be added to the official list of habitats due to updating the correspondence between Romanian and European habitats. As a first conclusion, this analysis phase will be consolidated during the next estimated monitoring phase (6 years later), meant to facilitate keeping track and monitoring biodiversity conservation in the protected area - Macin Mountains National Park.

\subsection{Dissemination and sharing using geoportal application}

Geoportal application which represents the public side of the biodiversity system is a single point of access to our biodiversity geospatial data, Web services, and other geospatially related resources. Put more simply, this geoportal is a Web site where geospatial resources can be discovered and, eventually, used [9]. Users can perform a search in the following ways:

- Visiting the geoportal web site, they can specify their search criteria and review the search results. 
- $\quad$ Users can install plug-ins, widgets for HTML and using the geoportal Flex-based Map Viewer, and then search for geospatial resources and use these discovered resources directly in these client.

- $\quad$ The REST interface opens an array of possibilities to integrate with other application environments.

The geoportal provides a variety of geospatial web services from ArcGIS Online, ROEnv Geoportal application hosted by Ministry of Environment and Climate Changes and INIS GeoPortal [10] managed by the National Agency for Cadaster and Land Registration (ANCPI). Acting as a broker between "Macin Mountains" National Park Administration (as content provider) and users, the geoportal application represents an important and highly visible component of SDI, serving as the "face" of SDI [11]. Despite the challenges, the benefits of the geoportal are clearly demonstrated in the positive results of the Scientific Council of the protected areas and can provide also support to other governmental initiatives and new opportunities for our national society as a whole.

\section{CONCLUSIONS}

The results of our spatially enabled framework for habitats and species management system, implemented through the above tiered approach represents a major advance in dissemination and sharing the conservation management resources using the web service technology principles. All geospatial web services behind our architecture are the building blocks for mashups, a basis for other cloud-based GIS systems and the foundation for the next generation of our National Spatial Data Infrastructure and other national and European integrated environmental related systems, such as SEIS (Shared Environmental Information System) [12]. We do consider that this type of mutual collaboration will maximize society's return on geospatial investment.

The proposed web services oriented architecture framework has also the following advantages over current practice:

- $\quad$ Facilitates geospatial information sharing and provides resources for developing other web GIS applications.

- $\quad$ Reduces errors by decreasing latency between collection and data storage process, as well as paperwork.

- Allows prioritization for the natural resources allocation to achieve the conservation status.

- Supports effective communication between different staff at different locations (e.g. scientists, biologist in the field, scientific council in the office, stakeholders at their headquarters).

- $\quad$ Saves time and money by reducing paperwork and allows staff to collect data and access the geospatial information anywhere at any time.

- Assesses the effectiveness of the conservation status management and environmental related policies.

Implementing an inventorying and monitoring systems based on our proposed solution for each protected area at local and regional level will also provide the mechanism for the Ministry of Environment and Climate Changes to ensure accurate and up-todate information resources regarding flora and fauna conservation status at national level.
Our next steps are focused on integration of these implemented web "services pattern" solutions into a national integrated biodiversity management system and to support the collaborative efforts to ensure the objectives of our National Spatial Data Infrastructure implementation.

\section{ACKNOWLEDGMENTS}

The authors wish to acknowledge the contributions and support from our scientific project experts - Multidimension and "Macin Mountains" National Park Administration. The project is under the Sectorial Operational Program "Environment" (SOP ENV) Priority Axis 4: "Implementation of adequate management systems for nature protection".

\section{REFERENCES}

[1] Common Standards Monitoring for Designated Sites http://jncc.defra.gov.uk/page-2217. (accessed on June $27^{\text {th }}$, 2014)

[2] INSPIRE Data Specification for the spatial data theme Protected Sites version 3.1.0 http://inspire.ec.europa.eu/documents/Data_Specifications/I NSPIRE_DataSpecification_PS_v3.1.pdf. (accessed on June $27^{\text {th }}, 2014$ )

[3] European Habitats Directive 92/43/EEC on the conservation of natural habitats and of wild flora and fauna; Birds Directive 2009/147/EC on the conservation of wild birds

[4] EEA reference grid samples for projection ETRS89-LAEA $52 \mathrm{~N} 10 \mathrm{E}$

http://www.eea.europa.eu/data-and-maps/data/eea-referencegrids. (accessed on June $27^{\text {th }}, 2014$ )

[5] Nicolae, D., Popescu, A., Pauca, M., Mihailescu, S. 2007. Interpretation Manual of European Union Habitats-EU27.

[6] CORINE Biotypes. 2000. The design, compilation and use of an inventory of sites of major importance for nature conservation in the European Community (version 2000) http://www. eea.europa.eu/data-and-maps/data/corinebiotopes. (accessed on June $27^{\text {th }}, 2014$ )

[7] Causton, D. 2008. An Introduction to Vegetation Analysis: Principles, Practice, and Interpretation. Unwin Hyman, London.

[8] Borza, Al., Boscaiu, N. 1965. Introducere in studiul covorului vegetal. Academia Republicii Populare Romane.

[9] Tait, M. G. 2005. Implementing geoportals: Applications of distributed GIS, Computers, Environment and Urban Systems 29 (1), 33-47.

[10] Romanian INIS Geoportal adopted by the National Agency for Cadastre and Land Registration (ANCPI) http://geoportal.ancpi.ro/geoportal/catalog/main/home.page (accessed on June 27th, 2014)

[11] Winnie, T., Selwood, J. (2005). Spatial portals: Gateways to geographic information.Esri Press, California.

[12] Shared Environmental Information System, http://ec.europa.eu/environment/archives/seis/index.htm (accessed on June $27^{\text {th }}, 2014$ ) 